\title{
DEL BIOMECANICISMO AL BIOTECNOLOGISMO EN LA BIOMEDICINA ILUSTRADA ESPAÑOLA
}

\author{
José María Rodríguez Merino
}

La modernidad y el tono revolucionario de la ilustración española no sólo se dilucidan por la introducción y divulgación del biomecanicismo sino que se prolongan en la construcción de una biología teórica no-reduccionista. Tal construcción supone un progreso epistemológico para la biomedicina ilustrada que deriva en el avance para la ideología moderno-ilustrada y en una utilidad sanitaria para la sociedad española de la época.

Para enmarcar el proceso y progreso epistemológico de la biomedicina ilustrada en España, nada mejor que comenzar con la comparación que propuso Francisco Bacon (1561-1626) en el libro I, aforismo 95 del Novum Organum (1620) donde expresa que: «las ciencias han sido tratadas o por empíricos o por dogmáticos. Los empíricos son semejantes a las hormigas que sólo recogen y gastan; los racionalistas son como las arañas que forman telas que sólo sacan de sí mismas; los verdaderos filósofos deben de ser como las abejas que están entre medias de las dos anteriores, pues la abejas recogen sus materiales en las flores de los jardines y los campos, pero las transforman y las destilan mediante un poder que les es propio". 
Con esta base comparativa de hormigas, arañas y abejas se puede obtener la estructura, proceso y progreso de los distintos modelos epistemológicos que se sucedieron en la biomedicina ilustrada española.

A fin de buscar una mayor correspondencia entre la trilogía baconiana y nuestro estudio en el período ilustrado invertimos un poco el orden propuesto por Bacon, pero en nada merma la representación histórico-filosófica. Así colocamos primero el modelo racionalista que está en perfecta consonancia con el análisis del biomecanicismo. Este es un modelo "araña» al que se adhirieron los biomédicos ilustrados de la primera mitad del s. XVIII y que profesaron el racional mecanicismo. Estos explicaban la actividad animal únicamente por razones y análisis que sacaban de su propia mente. Es el modelo que representa al progreso individual del conocimiento.

Por otra parte, están los biomédicos que superaron el biomecanicismo y practicaron el modelo «hormiga» o bioempirismo, cuya época corresponde aproximadamente a todo el siglo XVIII, esto es, los médicos que solamente se dedicaron a hacer experimentos para curar las enfermedades y recogieron su recompensa en la utilidad de devolver la salud a los enfermos, a la vez que avanzaron en biomedicina por el hecho de acuñar nuevos conceptos biológicos, lo cual supuso un progreso en la biología teórica.

Por fin, ya en las últimas décadas del XVIII y primeras del XIX hubo ciertos biomédicos ilustrados que tuvieron la feliz idea de realizar una íntima unión entre los dos modelos anteriores, el racional mecanicista y el experimental, los cuales están representados en el modelo «abeja». De este modo algunos biomédicos ilustrados hicieron realidad la unión de la tecnología y la experiencia para transformar la materia viva organizada. Entre otros ejemplos se pueden citar la vacuna antivariólica, las transfusiones de sangre, la fecundación artificial en los animales, etc... A este tercer modelo lo denominamos biotecnologismo, que representa el progreso social del conocimiento y su utilidad.

Bajo estos presupuestos pasamos a desarrollar el tema, no sin antes advertir que ya hemos sentado dos precedentes en el intento de construir una biología teórica, con nuestros trabajos: G. A. Borelli: un intento de aplicación del mecanicismo a la Biología en el s. XVII (1983-Tesina) y Aplicación del modelo mecanicista a la biomedicina en la ilustración española (Tosca, Zapata, Martínez, Feijóo, Arnau, Piquer) (1989-Tesis). 


\section{El biomecanicismo como modelo moderno y progresista}

\subsection{Introducción y divulgación del biomecanicismo en España}

El modelo mecanicista ideado por Descartes en el Tratado del Hombre (escrito probablemente en 1632 pero publicado en 1662) pronto se extendió por toda Europa y, por supuesto, como tratamos de demostrar, llegó a España. En la primera etapa de la introducción y divulgación del biomecanicismo en España, que se sitúa entre 1700-1730, uno de los grupos que destacó fue el de la Academia de Matemáticas de Valencia. Entre los miembros de esta Escuela sobresalió T.V. Tosca (1651-1723) que divulgó el mecanicismo del De motu animalium (1680) de J. A. Borelli en el Compendio Mathematico (1707-1715, vol. III, Tratado IX de la Maquinaria) y en el Compendium Philosophicum (1754, vol. VII, lib. III, cap. III) (1). En este grupo se encontraba J. B. Corachán (1661-1741) que también sacó a la luz las ideas sobre el movimiento de los animales de Borelli en la exégesis IV de Mathesis sacra (redactada en 1725 pero publicada en 1757).

Otro de los focos de divulgación del mecanicismo en España se centró en la Regia Sociedad de Sevilla (1700). Se ha de destacar a D. M. Zapata (1664-1745) (2) como miembro distinguido de esta Escuela en la lucha por reemplazar al galenismo por el sistema biomecanicistaiatroquímico. Este médico de Murcia, después de ser galenista en Verdadera apología de la Medicina racional (1690), pasó a defender las ideas iatroquímicas en Crisis médica sobre el antimonio (1701), a la vez que se declaró partidario del atomismo de Maignan en su Censura (insertada en los Diálogos filosóficos en defensa del atomismo (1716) de Alejandro de Avendaño). Es más; Zapata, ante las críticas de galenistas como Martín de Lessaca, volvió a reafirmar el biomecanicismo en su último libro Ocaso de las formas aristotélicas (1721).

Un ejemplo de profesión mecanicista que no se puede pasar por alto fue el médico madrileño Martín Martínez (1684-1734) (3), que como Zapata se había educado en la medicina tradicional-galenista para criticarla en Medicina Sceptica I-II e inclinarse en Anatomía completa del hombre (1728) por el corpuscularismo. Esta era para Martínez la teoría más racional y científica con la que se podía explicar el movimiento de los animales sin recurrir a las cualidades ocultas, facultades, potencia, virtud u otros términos que no explicaban nada. A pesar de su fondo escéptico, Martínez describió por medio del modelo biomecanicista los movimientos de la circulación de la sangre, la contracción 
muscular y la generación. El hecho de que Zapata y Martínez se inclinasen por la teoría corpuscular para explicar la actividad animal radica en que este modelo determina de manera precisa tan to los elementos explicativos como sus relaciones. Por ejemplo, en las secreciones ya no hará falta recurrir a las explicaciones dogmáticas, vagas e imprecisas de la facultad secretriz sino que se explicará por el acoplamiento que hagan los corpúsculos que se deben filtrar por los poros; esto obedece a que se había llegado a idear un modelo formalizador tanto para las combinaciones de los elementos naturales como artificiales. Este modelo se describía como preciso desde el punto de vista matemático, exacto en sus movimientos y concreto en sus funciones tanto en sí mismo como en sus relaciones. No obstante, toda esta determinación y relación propia de lo que constituye el proceso secretor se obstruye y se desordena cuando llega la enfermedad.

La concepción determinada y precisa de las explicaciones y sus relaciones en el modelo biomecanicista iba configurando la idea de que España se había sumado a la ola de la modernidad ilustrada europea.

\subsection{Marcha triunfal del biomecanicismo}

El camino estaba preparado y fue a partir de 1730 hasta 1755 cuando comenzó a consolidarse el biomecanicis mo. Ello se debió a que mientras los médicos de la primera etapa (1700-1730) habrían abierto el camino a la introducción y divulgación de este modelo, los de la segunda (1730-1755) lo asumieron y aplicaron como hipótesis de trabajo para resolver y explicar los problemas médicos. Por tanto, el hecho de que el biomecanicismo se consolidara en estas décadas centrales reside en la aceptación de la teoría biomecanicista por algunos médicos que impartían su docencia en las Facultades de Medicina del país, pues el modelo biomecanicista había dejado de ser ya monopolio de biomédicos ilustrados o eruditos que regentaban las Academias o Regias Sociedades. A la vez se debe de reseñar que a causa de este modelo se levantaron fuertes polémicas y críticas públicas no sólo entre galenistas-biomecanicistas sino entre biomecanicistas y experimentalistas. Por otra parte, estas polémicas trascendieron los foros propios para pasar a ser problemas sociales, religiosos o políticos. Las ideas mecanicistas fueron divulgadas principalmente en el Diario de los literatos (desde 1737) y Efemérides barométrico-médicas matritenses (desde 1737). 
Mientras la Regia Sociedad de Sevilla fue quedando rezagada en cuanto a la divulgación del modelo biomecanicista, el grupo de médicos ilustrados de Valencia logró abrir las puertas de la Universidad al biomecanicismo como teoría moderno-ilustrada así como el de Madrid. Entre los cultivadores del mecanicismo en Valencia están J. Arnau $(+1737)$ y A. Piquer (1711-1772). Ambos se dieron cuenta de que para progresar en Medicina había que sustituir las teorías metafísicas de la física por el desarrollo matemático y mecánico de la misma, lo cual iba a beneficiar al estudio de los fenómenos anatómicos y fisiológicos. De ahí, que para Arnau (Opus Neoteoricum I, 1737) las cosas naturales sean tales no en cuanto su esencia, sino en cuanto poseen la dimensión de ser extensas, en su triple forma de largas, anchas y profundas, además de estar dotadas de movimiento local y figura geométrica, con lo cual deja entrever su profunda influencia cartesiano-bagliviana. Un ejemplo claro de la emancipación de la física esencialista es la interpretación del magnetismo; ya que según los galenistas la atracción magnética se debía a las cualidades simpáticas, mientras que Arnau explicaba que esta atracción magnética se realizaba por la aceleración de los movimientos de los corpúsculos. Sin duda, es una interpretación más científica y sirve de base para explicar de modo racional actividades orgánicas como las secreciones.

El hecho clave en la obra de Arnau es el estudio de la fibra que llegó a ser el avance fisiológico más importante de los ss. XVII y principios del XVIII. La fibra muscular era para los médicos ilustrados lo que constituía la base material de todo el organismo y sus movimientos derivaban únicamente en un puro automatismo fibrilar. Se deduce por ello que él definiera al animal como "un cuerpo viviente provisto de sentidos y movimiento, que posee un singular tejido tanto en las partes musculares y nerviosas como en las fluidas y sólidas, lo cual no es otra cosa que una máquina artificial con sus diversos movimientos» (4). Por tanto, Arnau siguiendo a Descartes y Baglivi concebía al animal de modo artificial y analógico cuyos movimientos se equiparaban al automatismo de una máquina.

Intimamente ligado a Arnau en la cuestión mecanicista estuvo Piquer (5) que siguió de igual manera este modelo en su primera etapa valenciana (1734-1751), aunque fue más ecléctico que Arnau, porque recogió la doctrina no sólo de Baglivio sino también de Borelli, Hoffmann y Boerhaave. Comenzó con Theses Theorico medicae (1734) y en ellas se aprecia el progreso epistemológico que deseaba para la medicina; en el opúsculo expuso XV tesis de corte galenista y en las restan- 
tes intentó abrirse camino al eclectismo basándose para ello en el sistema biomecanicista. Es más, en 1735 se confesó solidista y defensor del biomecanicismo en Medicina vetus et nova; obra en la que concibe al cuerpo humano como una máquina que se mantiene por el equilibrio entre los sólidos y los líquidos. Asimismo el modelo mecanicista se fue consolidando en la Universidad valenciana cuando Piquer ganó la cátedra de Anatomía con Theses medico anatomicae (1742), y enseñaba dicha disciplina bajo las leyes del mecanicismo, especialmente en los ejemplos de la contracción muscular, la generación y la circulación de la sangre.

Sin embargo, para enseñar anatomía bajo las leyes mecanicistas los médicos ilustrados como Arnau y Piquer eran conscientes de que los alumnos debían aprender antes la física moderna. De ello es buen ejemplo Física moderna, racional y experimental (1745). El objetivo de Pique en esta obra era el ofrecer un curso sobre medicina moderna según las leyes del mecanicismo, ya que este modelo servía mejor para conocer la máquina humana y explicar sus operaciones a través de las leyes físico-mecánicas del movimiento. Un ejemplo que ponía el médico valenciano sobre las leyes físicas aplicadas al organismo era el saber por qué los glóbulos rojos se golpean contra las arterias y pasan a ocupar el fondo tubular mientras que los blancos suben arriba. El secreto está en el peso.

El momento central del mecanicismo piqueriano se puede enmarcar en los manuscritos inéditos, escritos hacia 1748, como Tractatus phisico-medicus de humani corporis mecanismo, De mecanismo corporis humani in statu morboso y Catalogus celebriorum Medicinae auctorum cum notiis criticis (6). Estos manuscritos inéditos y otros no encontrados todavía (Chinchilla, III, pp. 462-5) constituyen la base por la que Piquer enseñó el mecanicismo en la Universidad valenciana, pues por medio de ellos explicaba las operaciones fisiológicas del cuerpo humano. Esto demuestra que Piquer no sólo llegó a ser un introductor y divulgador del mecanicismo de Borelli y Boerhaave en la Universidad, sino que de hecho fue un aplicador de este modelo a la biomedicina ilustrada; porque lo consideraba como un sistema más racional y moderno para explicar los movimientos del animal que las facultades de los galenistas, y con ello sentó las bases para el progreso epistemológico de la biomedicina ilustrada española.

Por fin, el Tratado de las calenturas según la observación y el mecanismo (1751) fue la última manifestación mecanicista de Piquer en Valencia, que no es más que un resumen en lengua castellana de sus trabajos anteriores escritos en latín. Piquer en esta obra comenzó a poner 
de manifiesto sus diferencias entre el racional mecanicismo, o mejor dicho, entre el modelo ideal mecanicista y el empirismo o la realidad biomédica, ya que después de década y media de adhesión total al sistema biomecanicista empezaba a saber que la medicina es útil cuando cura las enfermedades y no cuando explica de modo admirable los movimientos del animal. Ello le condujo al nuevo concepto de naturaleza que llegó a idear debido a su modernidad biomédica, en la que las operaciones corporales se explican según sus estructuras mecánicas y se observan según las reacciones de la materia viva organizada. La naturaleza orgánica, así concebida y observada, no es más que un equilibrio entre sólidos y líquidos que funcionan en orden y correspondencia. Pero cuando este orden se altera viene el desequilibrio entre las partes y trae consigo el desorden y por consiguiente el proceso que se llama enfermedad. El retorno a la salud requiere devolver el orden y el equilibrio a las distintas partes del organismo.

En suma, se puede afirmar que Arnau y Piquer marcaron desde la Escuela Valenciana la pauta de la modernidad biomecanicista-ilustrada. Esto no quiere decir que fueran ni los únicos ni los primeros biomédicos que aplicaron el biomecanicismo a la medicina. Además de Tosca y Corachán hay que citar a Gregori Marciá en Dissertacion chirurgico Mecánica (1741) y a Mariano Seguer en Theoria galénico mechanica... (1746); sin olvidar al murciano Juan Jiménez Molina en Cartilla fisiológica galénica espagírica-matemático-médica (1730).

Un poco más alejados de tierras valencianas es obligado reseñar como cultivadores del mecanicismo en su etapa clave, a Antonio María Herrero en Física moderna experimental y sistemática (1737), y a Pedro Fermín Zurbano, médico de Pamplona, en Miscelánea dissertativa médico-mecánica: empeño médico por el desempeño médico para saber saber (1745). Este libro, como dice su título, es una «miscelánea» o tratado de varias materias fisiológicas, tales como la circulación de la sangre y la generación humana; y no tiene más propósito que interpretar el origen, naturaleza y valoración de estos problemas biomédicos desde el modelo biomecanicista.

Otro autor a tener en cuenta es Francisco Alonso Esteban García Lecca $(+1774)$ que en Escrutinio phisico-mechanico-chimico (1753) trató de modo mecánico el uso de las aguas minero medicinales para los distintos órganos de la máquina corporal. Problema que corría parejo con Demostración físico-mecánico-médico del provechosísimo natural y verdadero sistema del Dr. D. Vicente Pérez... (1753) de Gómez Arias. A V. Pérez se le ha considerado como el médico del agua y Gómez Arias 
confirmó la elección del agua en sus distintos estados de fría, templada o caliente junto con sus propiedades medicinales como principio para suavizar la inflamación, o mejor dicho, la contracción desordenada y violenta de las fibras musculares, ya que oprime de tal manera a los vasos sanguíneos que coarta la circulación de la sangre y como consecuencia viene el dolor, la hinchazón, el pus, etc...

Del mismo modo Manuel de la Chica y Ulloa, miembro de honor de la Academia de Medicina de Madrid, se planteó el problema de la sangría por medio de las Dissertaciones físico-mecánico-anatómico-médicoteórico-prácticas según la observación y el mecanismo (1754) en la que defendió que las calenturas pueden llegar a curarse por métodos distintos de la purga o la sangría. Con el mismo modelo mecánico interpretó las inflamaciones Rafael de los Reyes Sahagún en Tratado de las inflamaciones internas, explicadas por leyes mecánicas e ilustradas con observaciones y estractos doctrinales (1754). Estas explicaciones proceden de las observaciones que realizó como médico en Extremadura, asegurando que esta clase de enfermedades eran las que afloraban con más frecuencia en el territorio extremeño. En la misma línea mecanicista estuvo también Antonio Segarra con Disertación histórica sobre la inflamación y sus remedios según el mecanismo del cuerpo humano (1772).

No se puede pasar por al to que Madrid con su Academia de Medicina (1732) y la Sociedad Médica de Nuestra Señora de la Esperanza (1743) estuvo en la ola de la introducción y aplicación del modelo mecanicista a la biomedicina en la ilustración española. Sus miembros fueron seguidores del biomecanicismo y algunos pertenecientes a ambas sociedades médicas como el acérrimo seguidor del biomecanicismo Miguel Rodríguez o su crítico Pedro Bedoya y Paredes. Lo que históricamente no está aclarado es saber por qué se fundó la Sociedad Médica de N.S. de la Esperanza en 1743 habiéndose fundado la Academia de Medicina en 1732, ya que ambas cultivaban la doctrina mecanicista y muchos médicos eran miembros de las dos.

En cuanto a Miguel Rodríguez $(+1740)$ hay que decir que fue uno de los máximos representantes del biomecanicismo madrileño en Dissertatio phisico-mechanico-medica de usu et abusu sanguinis misionis, (1740). En esta obra se declaró incondicional defensor del mecanicismo, y para ello puso como pretexto el abuso que hacían de la sangría los médicos galenistas. Estos, sin atenerse a las leyes mecánicas de la naturaleza ordenaban sangrar en cualquier enfermedad o, por el contrario, también criticó a los médicos experimentalistas que sin tener en cuenta el movimiento circular de la sangre apenas si mandaban san- 
grar en alguna ocasión. De cualquier modo, para curar las enfermedades M. Rodríguez exigía que el médico se apoyase en el sistema mecanicista de tal manera que, como todos los biomecanicistas puros, consideraba a este sistema como necesario y suficiente para explicar todos los movimientos de los animales.

Por otra parte, entre los objetivos de M. Rodríguez al fundar la Sociedad Médica de N. S. de la Esperanza pudieron estar la introducción de nuevas doctrinas europeas, la resolución de problemas muy prácticos y difíciles o el impulso de la renovación técnica en la medicina. El primer problema que se plantearon los fundadores de la Sociedad Médica fue el de introducir y divulgar por medio de traducciones los progresos médico-filosóficos que se estaban haciendo en Europa para curar ciertas enfermedades difíciles. Así una de las primeras tareas que realizó Ignacio Moguel fue la de traducir la obra del siciliano Domenico Talia: Disertación físico médico-anatómica en respuesta a la pregunta hecha por la sociedad médica de la Esperanza: ¿Por qué siendo el regular domicilio de las lombrices el canal intestinal producen picazón en las narices?, o también la traducción que hizo A. Fernández de Lozoya de la obra de J. M. van Berhman titulada: Disertación de las verdaderas razones mecánicas de los apetitos invertidos y depravados en las preñadas.

Después de estas traducciones la pregunta sobre el problema de las lombrices fue lanzada a todos los miembros de la Sociedad Médica con el fin de que aportasen mayor luz sobre ella. Para ello, la misma Sociedad ofreció un premio al mejor trabajo, y cada miembro de la Sociedad tenía la obligación moral de responder como participante activo de dicha comunidad científico-médica. La mayoría respondió pero de manera distinta como se puede apreciar. Así, Miguel Rodríguez escribió una memoria encargada por la Sociedad y titulada: Complemento de la historia de las lombrices delineado de orden de la real sociedad médica de la Esperanza (1754), en la que expuso las clases de lombrices que hay, enfermedades que producen y sus remedios, junto con varias opiniones sobre el tema de autores antiguos y modernos. Otra disertación sobre el tema fue la que hizo Diego Torres y Villarroel en Respuesta de D. Diego Torres a la pregunta que hacen los señores médicos socios establecidos en Madrid en la real congregación de Nuestra Señora de la Esperanza, la cual es: ¿por qué siendo el regular domicilio de las lombrices el canal intestinal comúnmente producen picazón en las narices? (1750). Escribió esta disertáción en tono humorístico y no con ánimo de ganar ningún premio sino con el fin de estimular a los 
médicos a que presentasen los trabajos sobre el problema y recibiesen la recompensa ofrecida por la Sociedad médica.

Un planteamiento distinto del problema lo llevó a cabo Pedro Llorente con Respuesta del Dr. Pedro Llorente, médico que fue de los reales hospitales, a la pregunta qué hacen los Srs. médicos socios, establecidos en Madrid en la real congregación de Nuestra Señora de la Espe. ranza: la cual es, por qué siendo el regular domicilio el canal intestinal, comúnmente producen picazón en las narices... (1750). En esta obra Llorente no avala la hipótesis, como algunos sostenían, de que la causa del picor de las lombrices se debiera a las picaduras que producen estos anélidos en las túnicas intestinales las cuales se propagan por el movimiento antiperistáltico, ni tampoco a los fenómenos de las ondulaciones nerviosas cuya causa buscaban afanosamente algunos miembros, sino que para Llorente la causa del picor podía estar en un suero acre que emana de la fermentación del líquido que depositan los insectos al picar la nariz y que transita por la pituitaria.

Sobre este tema tampoco se debe olvidar la interpretación que dio Francisco Rubio en su Disertación físico-médico-meçánico historial del origen, generación y efectos de las lombrices y su curación... (1750), en la que supone que el canal intestinal forma un todo con la membrana de la pituitaria y al formar esta unidad llegaba a picar por causa de las ondulaciones nerviosas, las cuales sólo alcanzan a estimular las fibras nerviosas con ligeras sensaciones y, por tanto, no irritan a las túnicas membranosas, como sucede en las inflamaciones por cólicos, hernias, etc. que producen irritación y mucho dolor. Se puede decir que el médico de Játiva se propuso escribir esta obra más para cumplir con las obligaciones que mandaba la Sociedad que para dar una respuesta al problema, pues para él ya había respondido suficientemente Torres y Villarroel.

Con la misma solidaridad de responder como socio de una comunidad científica viva afrontó el problema de las lombrices Gómez Arias. Este lo planteó en Respuesta de D. Gómez Arias a la pregunta hecha en la Gaceta del día 6 de enero de este presente año por los señores médicos socios de la real congregación de Nuestra Señora de la Esperanza; la cual es: ¿Por qué siendo el regular domicilio de las lombrices el intestino colon, se siente comúnmente picazón en las narices? (1750). El profesor de matemáticas trató el tema de modo imaginativo y sin base médicoexperimental, porque ubicaba a las lombrices en el intestino y en el cerebro, e interpretaba que estos anélidos bajaban del cerebro debido a la serosidad y humedad que hay en él para refugiarse en la nariz, donde al no encontrar linfa excita las fibras nerviosas y se produce el picor. 
También José Miguel Royo dio Respuesta a la pregunta que hacen los señores médicos socios, establecidos en Madrid en la real congregación de Nuestra Señora de la Esperanza. ¿Por qué siendo el regular domicilio de las lombrices el canal intestinal comúnmente producen picazón en las narices? Aquí Royo, como buen mecanicista, explicó la manera de producirse esta picazón según el modelo biomecanicista. Sin embargo, Juan Ignacio Moguel fue quien ganó el segundo premio concedido por la Sociedad médica a su obra Disertación físico-médicoanatómica en respuesta a la pregunta... ¿Por qué siendo el regular domicilio de las lombrices el canal intestinal producen picazón en las narices? (1750). En este discurso Moguel trató de probar que la propagación del picor de las lombrices se lleva a cabo por medio del propio conducto intestinal, ya que éste pasa al estómago y de aquí a través del nervio intercostal se une con las fosas nasales.

Finalmente, y sin ser exhaustivos, se pueden añadir dos autores que también dieron su respuesta a la pregunta de la Sociedad. Estos son: Antonio Aguirre en Una disertación médica sobre las lombrices, y F. R. de los Reyes Sahagún en Disertación sobre las lombrices.

Es claro que a pesar de la revisión histórica de esta marcha triunfal del biomecanicismo por España durante las décadas de 1730 a 1755, no se ha intentado agotar el tema, pero sí se ha querido ofrecer un nutrido grupo de médicos con el que se ha articulado el proceso y progreso epistemológico de la biomedicina ilustrada en España. Por estas décadas comenzaron también a demarcarse los límites del ideal biomecanicista debido a su excesiva formalización de carácter racional, que para ciertos biomédicos que vamos a ver lo hacía poco menos que inútil al no poderse enfrentar a la realidad práctica de curar. Ante estos problemas no resueltos por parte de los médicos biomecanicistas comenzó a emerger el sistema experimentalista.

\section{Emergencia del bioempirismo}

El artificial biomecanicismo aplicado a la biomedicina supuso un cierto progreso epistemológico sobre el galenismo; sin embargo, los mecanicistas rígidos como M. Rodríguez consideraron al modelo biomecanicista necesario y suficiente para curar las enfermedades y explicar por medio de él todos los movimientos del animal. Esto, porque creían que el éxito que había tenido la aplicación de las leyes de la física mecánica al Universo se debía de repetir al aplicarlas a la biología. No 
obstante, la física mecánica, al ser aplicada a la biología, no se corresponde en su totalidad, porque la actividad animal aunque se ha explicado en términos reduccionistas, en esta misma época ilustrada hubo una reacción antirreduccionista debido a la emergencia del bioempirismo y el vitalismo. Ello obligó a muchos biomédicos ilustrados a reinterpretar el mecanicismo como modelo necesario pero no suficiente para explicar todas las actividades del animal, lo cual supuso una autocorrección en las explicaciones biológicas a problemas no resueltos por medio del modelo biomecanicista. Además, esto hacía que la ilustración fuese un período revolucionario debido a que la constitución teórica de la ciencia biológica no se produce de modo lineal, sino que progresa a base de modelos antagonistas como el galenismo y el biomecanicismo o de teorías rivales, contrarias y/o contradictorias como el galenismo, biomecanicismo o vitalismo. No obstante, estos sistemas, en virtud de la idea de modernidad y progreso que se daban en las distintas comunidades de biomédicos ilustrados, llegaron a ser complementarios.

El tránsito del modelo «araña» o biomecanicista, esto es, el razonador o ténico que se lo saca todo de su mente, al modelo «hormiga», es decir, al biomédico que experimenta para curar las enfermedades, supone un progreso epistemológico profundo en cuanto a la construcción teórica de la biología, ya que se pasó del racional mecanicismo al sensualismo y vitalismo por medio de la experimentación.

\subsection{Superación del reduccionismo biomecanicista}

Frente al racional mecanicismo que había imperado en toda la Europa continental con filósofos como Descartes y Leibniz y con biomédicos como Borelli, Baglivio, Boerhaave, Stahl y Hoffmann surgió el bioempirismo como sistema antagónico que venía de Inglaterra, siendo sus principales impulsores F. Bacon (1561-1626), J. Locke (1632-1704) y sobre todo Th. Sydenham (1624-1689).

El bioempirismo también llegó a España y lo podemos enmarcar desde principios hasta finales del siglo XVIII. Comenzó en la Regia Sociedad de Sevilla con el renacido hipocratismo de Boix y Moliner (1636-1722), en sus dos obras: Hipócrates defendido (1711) e Hipócrates aclarado (1716). En estos libros expuso sus ideas acerca de la necesidad de volver a la medicina experimental para poder superar a las vacías formalizaciones de los aristotélico-galenistas, es decir, que prefería embarcarse en una hipótesis de trabajo en biomedicina, aunque el ex- 
perimento fuera falible, antes que anclarse en los razonamientos especulativos de los galenistas. Con esta actitud Boix y Moliner, respaldado por la Regia Sociedad de Sevilla, abría una alternativa al galenismo como ya lo había hecho Sydenham en Inglaterra.

El trabajo de Boix y Moliner no fue valdío pues tuvo como seguidor a Martín Martínez, que en medio de su corpușcularismo y base escéptica, propugnaba la experimentación como base del progreso epistemológico de la biomedicina ilustrada. Otro autor que siguió esta doctrina bioempirista fue A. Piquer, que después de ser en su juventud un acérrimo defensor del biomecanicismo, en su etapa de madurez se pasó al bioempirismo.

Uno de los factores que influyó en la expansión del bioempirismo en la biomedicina de la ilustración española fueron los distintos médicos extranjeros que Felipe $\mathrm{V}$ había traído para curar a los heridos de la guerra de Sucesión, y por ello se quedaron aquí. Estos médicos eran grandes cirujanos ya experimentados en el campo de batalla, tales como Pablo Petit, Francisco la Rive, Juan Antonio Lafitte, Luis Dette, sin olvidar a Cervi, Kelly y Higgins; ellos trajeron las nuevas técnicas de Europa y bajo el patrocinio de los reyes crearon en los Hospitales nuevas secciones dedicadas a la cirugía. En definitiva, comenzaron a sustituir la medicina especulativa de los galenistas y la explicativa de los biomecanicistas por una medicina práctica y útil a la sociedad, basada solamente en la observación y el experimento.

Precisamente el tránsito del biomecanicismo al bioempirismo no se llevó a cabo por concesiones gratuitas de la comunidad de biomédicos ilustrados, sino que se hizo bajo arduas polémicas entre las comunidades de biomédicos que rivalizaban en sus teorías. Así, el biomecanicismo reduccionista de M. Rodríguez expuesto en Disertatio physicomechanico-medica de usu et abusu sanguinis misionis, habita in regia academia medica matritense (1740) pronto fue criticado por Pedro Bedoya y Paredes en Examen crítico de la sangría artificial (1740). Bedoya, al igual que M. Rodríguez, era fundador y secretario de la Sociedad de Nuestra Señora de la Esperanza, pero no participaba del ciego seguimiento del biomecanicismo como M. Rodríguez, aunque sí trataba de conciliar el biomecanicismo con el bioempirismo. Para él, la búsqueda de la certeza biomédica se basaba en dos pilares, la experimentación y la matemática: en la experimentación, porque el médico sólo puede llegar al conocimiento de la enfermedad por medio de repetidas óbservaciones; en la matemática, porque es la ciencia de la cantidad, número y demostración cierta. 
La diferencia entre concebir el organismo de modo racionalmecanicista o admitir la experimentación es grande en cuanto al conocimiento de las enfermedades se refiere, pues es lo que va de una concepción ideal a un conocimiento real. Con un ejemplo se puede ilustrar mejor esta diferencia, ya que si el organismo fuera tan solo un artefacto mecánico el desorden vendría por desgaste de sus piezas o por avería en alguna de ellas, pero si se observa la enfermedad en el organismo, ésta puede venir también por desgaste, pero este desgaste en la mayoría de los casos supone la inflamación de alguna de las partes del organismo. La hinchazón aumenta la dimensión de una o ciertas partes concretas que producen obstrucción en la normal operatividad mecánica del organismo, originando fiebre y con ello aceleración o en cierto modo disminución considerable del pulso, lo cual es un síntoma de que la enfermedad está presente. La observación del pulso debe ser para el médico la señal más certera para conocer si las fuerzas del organismo están en buen estado o se debilitan, mejoran o se agravan. De ahí que Bedoya (7) admitiera el principio de fuerza interna como propiedad de la materia viva organizada, ya que el pulso se autorregula debido a las fuerzas internas que contienen las fibras musculares, que son las que impulsan el pulso. Aquí se aprecia una diferencia notable entre idear el funcionamiento del organismo como un simple modelo racional-mecanicista - como quería M. Rodríguez- y concebirlo desde presupuestos empíricos o más realistas, es decir, dotado de fuerza interna en sus fibras musculares a causa de las propiedades biológicas de estructura y elasticidad que ellas poseen, como propugnaba Bedoya.

Bajo la misma base empirista Bedoya criticó la forma racionalmecánica de realizar la sangría por parte de M. Rodríguez, porque éste concebía al circuito mecánico de la circulación sanguínea como un modelo completo e integral y, por tanto, a la hora de ejecutar la sangría en las distintas enfermedades se podía seccionar por cualquier parte del circuito sanguíneo; por ello Bedoya censuró el modo indiscriminado de sangrar por parte de M. Rodríguez, tal como éste lo demostró en el ejemplo de las preñadas en peligro de aborto. En este caso M. Rodríguez recomendaba sangrar por el brazo, pero Bedoya insistió en que en el aborto, que es un caso muy particularizado, se debe sangrar porel tobillo y no por el brazo como sostenía M. Rodríguez; ya que éste consideraba a cualquier enfermedad como una causa generalizada y como consecuencia se podía sangrar por cualquier parte. Es más, a juicio de Bedoya, para realizar la sangría no sólo se debe de tener en cuenta el lugar de sangrar sino también el tiempo; esto es, siguiendo con el 
ejemplo del aborto, la sangría no.se puede prefijar matemáticamente, pues se deben de considerar las distintas variables del estado y salud de la gestante. Esto llevó a Bedoya a sostener que la realización de la sangría no debe de estar determinada sino que hay que dejarla indeterminada en el tiempo, por el hecho de que en el caso del aborto la sangría no está limitada a los cuatro primeros meses, porque se puede llevar a cabo en cualquier mes y dependiendo siempre de variables como el grado de salud y/o enfermedad de la gestante (8).

Como se puede apreciar, las críticas de Bedoya al biomecanicismo puro de M. Rodríguez servían para ir rompiendo el determinismo mecanicista al que había sometido a la biomedicina el médico madrileño.

Ante las certeras críticas de Bedoya en el Examen crítico (1740) contra la Dissertatio phisico-mechanico-medica (1740) de M. Rodríguez, éste viendo quebrarse su modelo biomecanicista no tardó en responder con Medicina palpable y escuela de la naturaleza donde se franquean importantes doctrinas y seguras reglas para el más recto uso de la sangría, ajustadas a las inviolables leyes del movimiento, con cuatro problemas Physico-Medicos y una dissertacion Mechanico Médica contra lo que establece el M.R.P.O. Antonio Joseph Rodríguez en el quarto tomo de su Palestra (1743). El fondo de la polémica seguía siendo el racionalmecanicismo llevado a ultranza por M. Rodríguez contra el bioempirismo y antisistematismo profesado por Bedoya. En éstas y otras polémicas se decidió la suplantación de la evidencia racional-mecanicista por la evidencia sensible al ejemplo de como estaba sucediendo en Europa.

M. Rodríguez siguió replicando en Medicina palpable que tanto los procesos bioempíricos como los químicos se sostienen sobre la palabra "sistema" y ésta se asienta sobre la debilidad de la analogía. De ahí que para interpretar la actividad animal no admitiera más sistemas que el mecanicista; éste superaba a todos, porque era «más brillante sin comparación que los otros y corría con más aceptación y aplauso por toda Europa» (9). Con esto, es claro que M. Rodríguez seguía teniendo al biomecanicismo como el único sistema con el que se podía explicar el funcionamiento del organismo, aunque desde 1740 se había comenzado a suplantar el mecanicismo por el bioempirismo.

Sin embargo, a pesar de la crítica que le había hecho Bedoya a M. Rodríguez sobre la sangría, éste en Medicina palpable la calificó de «loable» por considerarla como una polémica didáctica e instructiva, a la vez que se constituía como causa del progreso epistemológico de la biomedicina ilustrada. Pero M. Rodríguez no dudó en replicar a Bedoya 
con el fin de dar la «más cabal genuina y clara explicación de los phenomenos de la sangría por las inviolables leyes del movimiento para que admirase Bedoya las incomparables prerrogativas del Mecanicismo de las que están desnudos los demás Systemas» (10). Con Medicina palpable pretendía $\mathrm{M}$. Rodríguez que Bedoya se hiciese mecanicista.

Por otra parte, M. Rodríguez consideró útiles tanto a la sangría artificial como a la natural, porque si la naturaleza a veces evacua sangre por las narices o almorranas, también es necesario que el médico realice la sangría por medios artificiales como en el caso de las náuseas, dolores de vientre, calenturas, etc... No obstante, se reafirmó en su mecanicismo-reduccionista cuando propuso el ejemplo del reloj (Rodríguez, M. 1743, p. 160) para explicar las evacuaciones de la sangría artificial y natural ya que las comparaba al desorden que lleva un reloj cuando se avería y debe de ser desmontado por el relojero para reparar las piezas y devolverle el orden, la exactitud y simetría. Aquí se aprecia una vez más el reduccionismo de $\mathrm{M}$. Rodríguez, porque la sangría natural es efectuada por medio de una autorregulación que sólo puede realizar el organismo debido a sus propiedades biológicas; problema que estaba lejos de ser considerado por M. Rodríguez. Por medio de este ejemplo reduccionista del reloj, M. Rodríguez quería convencer a Bedoya de que el ideal mecanicista que suponía la analogía del animal máquina era el mejor sistema para explicar la actividad animal, mientras que Bedoya apelaba a la observación y experimentación como método más certero para progresar en el conocimiento de la biomedicina ilustrada. Por tanto, queda claro que el mecanicismo es necesario, en cuanto no se puede negar que el animal funciona igual a una máquina, pero se revela insuficiente para explicar toda la actividad animal; como se ha visto, el organismo es una máquina muy compleja que posee sus propiedades biológicas como la de autorregularse, la cual no se puede explicar ni reducir al sólo y simple concepto de mecanicismo.

Como ejemplo de su cerrazón al mecanicismo, M. Rodríguez, lejos de abrirse a otros sistemas, aceptó el encargo de la Regia Sociedad de Sevilla de redactar cuatro problemas «Physico mecánicos» en tono renovador y moderno, tarea que llevó a cabo con el propósito de divulgar y extender por toda España las ventajas del modelo mecanicista sobre los demás sistemas. Así en los Problemas-Physico-MechanicoMédicos-Theorico-Practicos (1743), y especialmente en la Dissertación Physico-Medica, M. Rodríguez aprovechó de nuevo la ocasión para exaltar las virtudes del modelo mecanicista frente al sistema galenista, quí- 
mico y experimentalista, cuando dijo que «el cuerpo del hombre es una animada machina de superior orden, compuesta de partes sólidas y líquidas. Saben que la vida de esta machina consiste en el incesante y recíproco movimiento de estas partes. Saben que la integridad, firmeza y feliz estado de esta fábrica, que es lo mismo que la salud del animal, estriva' en el orden, harmonía del movimiento de sólidos y líquidos, o en que no se venzan sus resistencias. Ultimamente saben que si entre ellas se pierde el equilibrio, enferma el viviente y si se eclypsa totalmente el movimiento, se arruina la machina y muere necesariamente el animal» (11).

Cuatro son los puntos principales sobre los que se apoyaba M. Rodríguez para fundamentar su biomecanicismo. El primero, que el hombre es una "machina animada», es decir, que la operatividad del organismo humano está sujeta a la constante intervención del alma, esto es, de una fuerza que no se identifica con la naturaleza humana sino que viene desde el exterior. El segundo es que concebía al cuerpo humano como una máquina de orden superior a la de los demás animales, lo cual confirma que M. Rodríguez era seguidor ferviente del modelo cartesiano. El tercero, que basaba su mecanicismo en el equilibrio entre sólidos y líquidos del que depende la salud, mientras que el desequilibrio entre ellos puede generar la enfermedad y hasta la muerte. Por fin, el cuarto es el movimiento local por el que se mueven las distintas partes del organismo.

En definitiva, M. Rodríguez basaba su mecanicismo en unos principios claros y en una evidencia de razón tal que redujo la actividad animal al racional mecanicismo. Para él, toda la naturaleza se sustentaba en las mismas leyes, es así que éstas habían sido instituidas por Dios, luego no podían contener falacia alguna, ya que de lo contrario aparecería como falaz el divino Geómetra. Por ello, dado el carácter divino de su naturaleza el biomecanicismo no podía contener error, sino que debía quedar totalmente a salvo por medio de la certeza racional. Esto hacía que M. Rodríguez defendiera el biomecanicismo a ultranza considerándole como el mejor de todos los sistemas, cuando dice: «a estos principios sencillos, evidentes y tangibles se reduce toda la Medicina mechanica. Si armado de ellas emprehende lid con las enfermedades un Médico docto, juicioso, prudente, de claro numen y bella sinderesis, puede ofrecerse el triunfo de los males mejor que con las falsas y morbosas armas de los demás systemas...» (12).

Esta concepción reduccionista de M. Rodríguez fue replicada por Bedoya en El médico desengañado y consejero de la verdad en el tribu- 
nal de la experiencia (1743), donde puso de manifiesto el carácter imaginario e ideal del sistema biomecanicista, y en el que criticó a M. Rodríguez porque no observaba la naturaleza orgánica. En concreto, éste negaba que los líquidos del cuerpo humano tuviesen sal, mientras que Bedoya había observado que la sal es necesaria tanto para la fermentación de la comida en el estómago como para la procreación y propagación de la especie humana, pues si el esperma careciese de sal se volvería estéril. De igual modo la sangre contiene sal, así como el quilo que se mezcla con ella. Además, Bedoya para fundamentar la evidencia sensible aconsejaba observar cómo las propias leyes del organismo van expulsando las partículas salinas que sobran del cuerpo, tales como por la orina, por la sangre en los menstruos, por el jugo pancreático, etc.; de lo contrario causarían enfermedad como cólicos, artrosis, reumas, etc. También demostró con evidencia experimental que para la curación de las calenturas se podrían utilizar tanto la sangría como el agua fría y la sal, así como que la saliva contiene sal que hace fermentar a los alimentos, o que el aire que se respira está cargado de nitro, a la vez que la sangre consigue sus fines de regenerarse y nutrir al cuerpo a base de ser portadora de elementos salinos (13).

En suma, Bedoya trataba de resolver con el sistema químico los problemas que no podía resolver M. Rodríguez con el solo mecanicismo, ya que el sistema químico, por una parte, complementa al sistema mecanicista y, por otra, lo reemplaza. El ejemplo es claro en el papel que juega la sal en la digestión, debido a que el ácido salino y/o jugo gástrico causa la fermentación de los alimentos. Este fue un progreso epistemológico de la biomedicina ilustrada española porque, al igual que en Europa, la digestión ya no se explicaba por medio de la oscura facultad concotriz, ni tampoco por la agitación corpuscular sino por el ácido estomacal. Este hecho instauraba un nuevo paso en el progreso de la ciencia química así como el inicio de lo que más tarde constituiría la bioquímica, sin olvidar que también se inauguraba una nueva era en la filosofía de la química que traía nuevos conceptos filosóficos como los de reacción y autorregulación. Estos procesos se producen al contacto de los distintos fármacos con el organismo y/o por medio de las segregaciones químicas que elabora el propio organismo para su autorregulación; esta función es distinta en cada caso de enfermedad e incluso en cada momento de salud. Ello indica que el organismo no es un mecanismo simple sino muy complejo que funciona a base del equilibrio de unos factores complementarios, de otros contrarios o hasta contradictorios. Este es también el modo como funcionó el progre- 
so epistemológico de la biomedicina ilustrada, es decir, a base de modelos complementarios como el sistema mecanicista y químico o antagonistas como el galenismo, mecanicismo y vitalismo.

\subsection{El rebrote antisistemático}

La polémica sobre el biomecanicismo lejos de apagarse continuó con el erudito en Medicina Antonio José Rodríguez (1703-1777). Debido a la menor divulgación de su obra este médico ha sido el gran desconocido en la ilustración biomédica española, ya que poseía una información mucho más actualizada y sistemática de las corrientes de la biomedicina europea que el propio Feijóo.

El médico de Veruela, a pesar de no ejercer la medicina se apoyó en el bioempirismo para criticar de forma puntual en su cuarto tomo de la Palestra critico-médica al biomecanicismo que profesaba M. Rodríguez y puso en evidencia lo artificial del modelo biomecanicista así como su inoperatividad para la medicina. Con ello no hacía más que superar a la medicina sistemática como ya lo estaban haciendo los médicos europeos, sobre todo los ingleses, por medio de la experimentación. Esto se debía al revivido neohipocratismo que corría por Europa como fuente y sistema que podía devolver la utilidad social que había perdido la medicina.

En el «Prólogo» del cuarto tomo de la Palestra (1741) se puede ver cómo al médico de Veruela no le interesaba seguir ningún sistema para curar las enfermedades, porque tanto el galenismo como el biomecanicismo y el sistema químico tenían algo de verdad pero ninguno la poseía toda. Confirma esto su postura antisistemática y ecléctica en el conocimiento de las enfermedades. La causa de que A. J. Rodríguez rechazase los sistemas como medio para conocer las enfermedades se debía a que la estructura del sistema es analógica, como la del biomecanicismo, y no real, es decir, que la medicina sistemática se fundamenta en el artificio y no en la observación y experimentación para progresar en el conocimiento de la verdad biomédica. Por tanto, el modelo del animal-máquina, ideado por Descartes y aplicado a la biomedicina por muchos médicos ilustrados, entre otros por M. Rodríguez, se iba desfondando debido a sus limitaciones racional-mecanicistas en el ejercicio práctico de la medicina. La sociedad ilustrada comenzaba también a exigir mejores y más prácticas atenciones en la sanidad pública. 
Se puede decir que A. J. Rodríguez rechazó con acierto histórico la aplicación a la biomedicina de todos los sistemas que habían sido cultivados hasta entonces, tales como el galenismo, el biomecanicismo y el químico, sistemas que tenían errores a la hora de curar las enfermedades. Así decía: «como se ha hecho moda el explicar ahora los phenomenos phatologicos y seguir la therapeutica sobre los principios y reglas geométricas y mecánicas, de modo que si el Médico no se explica para todo en el idioma Hecquetiano y Hoffmaniano no parece que podrá curar un panarizo, procuraré impugnarle...» (14). Es evidente que ante su postura antisistemática el médico erudito tenía como falibles a todos los sistemas de tipo racionalista, y de ahí que desaconseje a los médicos su uso en el ejercicio de la biomedicina.

Sin embargo, el médico de Veruela respetó, no sin críticas, el progreso epistemológico conseguido por la medicina sistemática, pues no dudó que el cuerpo de los animales es una máquina de perfecta simetría y organización, cuando dijo que el cuerpo «es máquina [...] es órgano donde juegan partes sólidas, fluidas y aéreas» (15), a pesar de que para él se ignorase todavía cómo se ordena y opera el modelo geométrico en el sistema orgánico. De tal manera que la aplicación de las leyes de la física mecánica para explicar los fenómenos biológicos, no deben de reducir tales fenómenos a simples operaciones físicas, como creyeron los biomédicos sistemáticos, sino que los fenómenos biológicos son consecuencia de la propia estructura del organismo. Por tanto, los sistemas no son la sola base por la que se gobierna la naturaleza y menos el funcionamiento sobre el que se debe apoyar el médico para curar las enfermedades, porque toda la compleja problemática de salud o enfermedad del organismo no se puede abordar desde las solas explicaciones del racional mecanicismo.

Es obvio que los principios mecánicos y los postulados matemáticos son ciertos y seguros considerados desde el punto de vista abstracto y racional, pero cuando son aplicados a una realidad tan tangible como es la biomedicina, aunque ellos son necesarios para explicar parte de la actividad animal, no llegan a ser suficientes para explicarlo todo, y menos en cuanto a enfermedades se refiere. Por todo esto A. J. Rodríguez sostenía que solamente es fundamento firme para la verdadera medicina «la historia, la observación [y] la práctica repetida» (16). En cuanto a la historia, la consideraba necesaria porque es importante que el médico sepa tanto el historial del enfermo como el de su familia o también que conozca cómo han resuelto los médicos el problema de ciertas enfermedades durante la historia. La observación constituía pa- 
ra él el método más apropiado para captar los síntomas de las enfermedades; una vez llevada a cabo ésta y realizado el diagnóstico se puede pronosticar la evolución de la enfermedad. Respecto a la repetición de los experimentos, opinaba que es el ejercicio que debe de imponerse todo médico con el fin de erradicar la enfermedad.

El bioempirismo y antisistematismo defendidos por A. J. Rodríguez en el cuarto tomo de la Palestra fueron criticados por M. Rodríguez en la Dissertacion Physico médica de la ventajosa verosimilitud firmeza y utilidad del Systema mechanico, respecto de los demás (17) que contiene la Medicina palpable (1743). Esta polémica se centra en que para el médico de Veruela el mecanicismo carecía de principios y leyes basadas en la realidad experimental de la biomedicina, y por tanto este modelo era incierto, mientras que $\mathrm{M}$. Rodríguez negaba que el modelo biomecanicista fuera falible por la sencilla razón de que la naturaleza ya le presenta como perfecto desde su creación. Es claro que el médico mecanicista argumentaba teológicamente, basado en la perfección que Dios infunde al cuerpo humano. No obstante, también reconoció las limitaciones del entendimiento para conocer perfectamente a la máquina humana. Tal es el ejemplo que muestran a diario enfermedades que se originan y se desarrollan en la máquina corporal que no se pueden curar. Esto llevó a considerar a M. Rodríguez que si el racional mecanicismo era falible para el conocimiento de las enfermedades, tan falible podían ser la observación y la experimentación, pues si nos engaña la razón los sentidos pueden hacerlo también.

La disertación de M. Rodríguez que defendía la utilidad y firmeza del sistema mecanicista no tardó el ser replicada por A. J. Rodríguez en el quinto tomo de la Palestra (1744) con otra Dissertacion apologética sobre la menos utilidad, firmeza, seguridad y más extravagancia del Systema Mecánico en la Medicina. La causa de esta inseguridad del sistema mecanicista residía para el médico de Veruela en su inutilidad y por tanto en el engaño al que se somete a los enfermos en un problema tan importante como el de su salud; ya que ningún médico deducía que las enfermedades se curan por el simple hecho de saber que el organismo es y funciona como una simple máquina. Es más, para.A. J. Rodríguez el mismo concepto de «sistema» constituía un reduccionismo al adaptarlo a cualquier doctrina, porque el hecho de aplicar una ciencia sin experiencia al conocimiento del organismo, éste queda reducido a algo ideal y que no le corresponde. Por otra parte, la palabra «sistema» se consideraba exclusiva en la época galenista y biomecanicista, esto es, se tenía como un modelo que podía conducir a la verdad 
dentro de la ciencia biomédica, y el resultado es que cualquier sistema es falible y por lo que toca al biomecanicismo es posible que más que ninguno.

En la «Proposición primera» de su Dissertacion Apologética A. J. Rodríguez planteó el problema de que el biomecanicismo se basa en la extensión, figura geométrica y movimiento local, y que tanto la geometría como la mecánica son ciencias que se basan en principios racionales, ciertos y evidentes, pero cuando éstos se aplican a las ciencias de la naturaleza biomédica se revelan defectibles y falibles. Esto indica que las leyes físico-mecánicas son lógicas pero que el organismo se rige en su funcionamiento por leyes bio-lógicas, y como consecuencia lo que por necesidad y lógica se sigue en la física mecánica no siempre puede seguirse en su aplicación a la biomedicina. Un ejemplo bastará para ilustrar la diferencia entre necesidad lógica y funcionalidad biológica. Así, a dos enfermos que tengan la misma enfermedad se les aplica el mismo remedio, y se dan casos en que ambos se curan, pero esto no sucede matemáticamente en todos, pues hay veces que el uno sana y el otro empeora o muere.

De igual modo, A. J. Rodríguez criticó a M. Rodríguez en la «Proposición quarta» sobre «Si el mecanicismo mathematico fuese necesario para sanar, todas las enfermedades Médicas serían incurables» (18). El médico de Veruela creía que el cálculo matemático a veces no se corresponde con la realidad natural; al citar a Tosca decía que «en materias physicas algunas veces no se puede llegar a aquella claridad y evidencia que tienen las demostraciones Geométricas [...] Lib. I de Static. [Tosca]» (19). Es evidente que si esto sucede en la aplicación de la mecánica a la física con más razón viene a suceder en el caso de la biomedicina. Y para fundamentar mejor su hipótesis A. J. Rodríguez se basó en Boerhaave (Elementa Chem., p. 346) que también había corroborado que para comprender y explicar las operaciones del organismo no bastan las solas leyes de la mecánica, porque en la máquina animal no se puede conocer con precisión cuál es el centro de gravedad, ni la magnitud de cada corpúsculo que se mueve dentro de los vasos, ni las formas inclinadas respecto a las funciones de vasos, cosa que sí puede conocerse si se calcula sólo de modo matemático.

El planteamiento que hizo A. J. Rodríguez entre lógica meçánica y bio-lógica era preocupación común de muchos biomédicos, ya que en definitiva afloraba el problema entre artificialismo biomecanicista y realidad biomédica. El médico de Veruela superó el problema por medio del bioempirismo. Esto trajo consigo nuevos conceptos biológicos, 
tales como el de irritabilidad, ya que gracias a la observación la fibra muscular dejó de ser una simple cuerda o varilla metálica y se descubrió que era irritable, esto es, que ante un estímulo es capaz de responder, porque posee una elasticidad, estructura y fuerza interna que sólo son propias de la materia viva.

Por ello escribió que en la enfermedad la «crispatura, oscilación, laxitud, que padecen los sólidos, son porque los líquidos viciados [...] los crispan, laxan y desentonan» (20). Aquí se evidencia que la irritabilidad de los sólidos la causan los líquidos.

Con estos brotes vitalistas, no en sentido animado, sino animal, A. J. Rodríguez hacía avanzar la epistemología biomédica ilustrada como antes lo habían hecho Baglivi y Arnau, teniendo como base fundamental a la materia viva organizada representada especialmente en la fibra muscular.

La polémica bioempirismo-biomecanicismo no se paró en A. J. Rodríguez y M. Rodríguez sino que la crítica que había realizado el médico de Veruela sobre la relativa inutilidad de las matemáticas aplicadas a la biomedicina fue respondida por Ignacio Catalán en su Medicina experimentada (1745); principalmente en la «Demostración Médico Mathematica» en la que prueba la utilidad de la aplicación de la matemática a la medicina. Catalán se basaba en que las matemáticas no sólo no falsean las operaciones biomédicas, sino que "de hecho se acomodan a las leyes de la naturaleza, tanto para conservarse en estado de salud, quanto para curarse en el de enfermedad» (21). Por tanto, es claro el uso de la matemática para que el médico progrese en el conocimiento de las enfermedades, pues la naturaleza está escrita en lenguaje matemático y la biomedicina no puede prosperar sin ella. No obstante, en la época ilustrada la biomedicina progresa a base de sistemas, por una parte rivales como el mecanicismo y el vitalismo, pero por otra complementarios.

Tampoco faltaron otras polémicas sobre la generación, regeneración y organización de la materia viva; todos, conceptos biológicos de los que prácticamente carecía el mecanicismo y denotaban la preocupación que tenía por ellos tanto la comunidad científica como la sociedad ilustrada española que no desmerecía de las polémicas que años atrás se habían dado en Europa.

Así en 1753 A. J. Rodríguez publicó su Carta-Respuesta en la que defendía la teoría «ovista» y excluia la «vermiculista», la cual fue puntualizada por García Hernández en Addicion y Apología. La puntualización consistió en que A. J. Rodríguez suponía creado inmediatamente 
«el individuo futuro [y García Hernández] formado por el generante» (22). El hecho de que A. J. Rodríguez supusiese creado al organismo del individuo de cada especie por Dios desde el primer instante, se debe a la defensa de la creación divina que él hacía, problema que García Hernández resolvió colocando el huevo en el esperma viril. Esto indica que eran problemas que preocupaban no sólo a la comunidad de biomédicos sino a la sociedad, pues era un problema que estaba relacionado con el «Discurso de la alma brutal» en Nuevo Discurso (1767); donde expuso la opinión de A. J. Rodríguez: por qué los animales no tienen alma sensitiva, ni son puras máquinas «sino máquinas animadas» (23). Porque si se concede alma sensitiva a los animales entonces hay que concederles el alma racional como a los hombres: éste era el mismo argumento sobre el que se había basado Descartes; pero A. J. Rodríguez superó a Descartes porque no concebía al animal como una pura máquina, sino como una máquina sensitiva al ejemplo de los pájaros cuando cantan. Este problema había traspasado también las reuniones de las comunidades de biomédicos y se discutían en las conversaciones familiares por la carga de materialismo o de fe que incluían, tal como lo habían expuesto ya Martínez y Feijóo (24).

Para finalizar, diremos que el largo camino del bioempirismo estaba abierto y a partir de 1750 fueron apareciendo otros autores. Por citar algunos de los más influyentes tenemos a A. Piquer (1711-1772) que, después de ser un ferviente seguidor del biomecanicismo en su etapa de Valencia, llegó a profesar el bioempirismo en su etapa de Madrid. El año clave del bioempirismo piqueriano fue 1752 cuando pronunció su Oratio quam de medicinae experimentalis praestantia, et utilitate. Piquer siguió esta teoría en Las obras de Hipócrates más selectas (1757-1770), Institutiones medicae (1762), Praxi medica (1764-1766) y sobre todo Discurso sobre el sistema del mecanicismo (1768) que es donde analiza más a fondo las ventajas del bioempirismo comparadas con las del biomecanicismo (25). Tampoco se debe olvidar a Gaspar Casal (1680-1759) que con su única obra Historia natural y médica de el Principado de Asturias (1762) no hizo más que un canto al progreso en el conocimiento de la biomedicina por medio de la experimentación, o a Francisco Rubio en el Arte de conocer y de curar las enfermedades por reglas de observación y experiencia (1761).

Fruto de los progresos biomédicos por medio de la experimentación fue la creación de la medicina clínico-quirúrgica, cuyos máximos representantes fueron Pedro Virgili (1699-1766) y Antonio Gimbernat (1734-1816). 


\section{El biotecnologismo como modelo simbiótico y productivo}

Desde 1770 hasta 1820 la biomedicina inauguró otra etapa que nosotros denominamos biotecnologista. El terreno científico y técnico estaba preparado, así como el social, debido a que los descubrimientos del s. XVII se habían comenzado a poner en práctica en el s. XVIII, al igual que socialmente se estaba poniendo de manifiesto la necesidad de unión entre la clase liberal y la artesanal, esto es, entre médicos y entre diseñadores técnicos con el fin de hacer progresar la biomedicina. Por tanto, es evidente que se daban las circunstancias históricas para una simbiosis o asociación entre racionalidad técnica y experimentación científica por necesidades militares, industriales, sanitarias y, sobre todo, por el interés que tuvieron Carlos III, Carlos IV y Fernado VII para sacar rentabilidad a las colonias americanas.

Sin duda, la gran ilusión de muchos biomédicos ilustrados empezaba a convertirse en realidad; ya que al tener una suficiente tecnología y una capacidad experimentadora dio como fruto la unión entre el biomecanicismo y el bioempirismo, que se plasmó en el nuevo concepto que nosotros denominamos biotecnologismo.

Entendemos por biotecnologismo el uso racionalmente controlado de la tecnología y la ciencia experimental aplicadas a la transformación $y$ explotación de la materia viva por lo vivo. Este modelo es el representado por la «abeja» que de modo instintivo sabe unir la experimentación, manifestada en los múltiples viajes que realiza para libar en las flores y frutos del campo, y la racionalidad técnica de saber construir una celdilla exagonal. Esta figura geométrica multiplicada por cientos llega a formar un panal que sirve a las abejas para depositar las libaciones transformadas en miel.

El modelo «abeja» es un modelo productivo que exige una biodirección ejercida por la reina sobre la colmena, a la vez que requiere una obediencia y conocimiento de todas y cada una de las abejas en sus deberes de libar para llevar a cabo la empresa de construir y llenar los panales de miel durante el año. La diferencia en cuanto al conocimiento y la formación del colectivo biosocial entre las abejas y el hombre, está en que el hombre es capaz de modificar, diversificar y autoinventar sus modelos y la abeja no lo demuestra porque siempre realiza el mismo.

Tampoco se puede olvidar que las transformaciones de la materia viva son muy antiguas en tanto en cuanto transformaciones de lo vivo por lo vivo. Las transformaciones pueden ser naturales, si las realiza 
la propia naturaleza: por ejemplo la transformación de las flores en miel por las abejas; o artificiales si las provoca el hombre con su tecnología, tal es el caso de las vacunas.

Con el paso del tiempo y la unión de la técnica y la ciencia experimental, la comunidad de científicos ha ido dominando y controlando cada día más la materia viva. Es claro que el período ilustrado constituye una época importante tanto en la divulgación como en el control de la materia viva organizada, de tal manera que se descubrió que la materia viva se irrita, se genera y además se regenera, se organiza y se autorregula. Todos estos conceptos son propios de la biología e incidieron de manera muy directa en el progreso de la utilidad y productividad de la biomedicina ilustrada, ya que ésta cada día se iba poniendo más al servicio de la sociedad. La modernidad explicativa del biomecanicismo fue superada por la modernidad utilitaria del bioempirismo y ambas por la modernidad productiva del biotecnologismo.

En esta época ilustrada los biomédicos comenzaron a tener más conciencia de la materia viva organizada debido al estudio de la irritabilidad en la fibra muscular. Como ejemplo se puede citar a Sebastián Guerrero Herreros (1720-1790) que fue una de las principales figuras científicas de la Regia Sociedad de Medicina de Sevilla durante la segunda mitad del siglo ilustrado. En la primera parte de Medicina universal (1774-1777) considera a la fibra como la estructura más básica de la materia viva organizada hasta entonces conocida. Las fibras musculares pasan de ser elementos puramente mecánicos a ser consideradas con propiedades biológicas como la irritabilidad. Estas propiedades fueron observadas por Guerrero a través del microscopio y comprobadas en cuanto a su irritabilidad (estímulo y respuesta) por distintas experimentaciones químicas.

Otro autor que se ocupó de la irritabilidad fue Ignacio María Ruiz de Luzuriaga (1763-1822) quien llegó a ser miembro de la Sociedad Vascongada de Amigos del País. La preocupación de Ruiz de Luzuriaga por la irritabilidad es clara desde que realizó su primer trabajo titulado: Tentamen medicum, inaugurale, de reciproca atque mutua systematis sanguinei et nervosi actione (1786), que fue su tesis doctoral. Trabajo que en 1790 tuvo que defender contra el plagio que le hizo el Doctor Girtanner en Paralelo de los experimentos que publicó el Doctor Girtanner en el Diario de la Física del mes de agosto de 1790 en su Memoria sobre la irritabilidad considerada como principio de vida en la naturaleza organizada, con los que publiqué en mi Tentamen Medicum inaugurale: de reciproca atque mutua systematis sanguinei et nervosi actione, impreso en 
Edimburgo en la Imprenta de Balfour y Smellie el 12 de septiembre de 1786, esto es, quatro años menos un mes antes que la Memoria del Doctor Girtanner.

Ruiz de Luzuriaga trató de demostrar en su tesis que inyectando con una jeringuilla graduada una cierta porción de gas nitroso en la vena yugular de un perro, el animal muere en poco tiempo, porque la sangre del ventrículo derecho se vuelve negra y se coagula, mientras que la del ventrículo izquierdo se pone de color pardo oscuro. Esto sucede porque el corazón del perro pierde toda su irritabilidad y como consecuencia le sobreviene la muerte.

Con este ejemplo experimental Ruiz de Luzuriaga quiso demostrar la estrecha relación que hay entre el sistema nervioso y la sangre, cuyo punto más particular es saber cuáles son los mecanismos que se dan en la respiración por parte de la química. Esto que hemos visto en el experimento del perro lo extendió a la realización de los experimentos in vitro con técnicas avanzadas, para saber la acción o presión de los gases sobre la sangre, tanto de la que corre por las arterias como por las venas. El flogisto de.G. Stahl fue la base teórica sobre la que se apoyó Ruiz de Luzuriaga.

En posteriores investigaciones como Dissertación chimica fisiológica sobre la respiración y la sangre consideradas como origen y primer principio de la vitalidad de los animales: leida a la Academia en 8 de abril de 1790 por el Doctor Don Ignacio María Ruiz de Luzuriaga, el médico de Villaro abandonó la teoría del flogisto por la del oxígeno de Lavoisier, que era la aceptada por la comunidad de biomédicos progresistas. En esta obra el biomédico vizcaíno determinó que tanto la sangre como la respiración constituyen el primer principio de la vida animal. De igual modo demostró in vitro la composición química del aire en una parte de oxígeno y tres de nitrógeno.

Sobre el experimento químico de la composición del aire, Ruiz de Luzuriaga montó su teoría de que la sangre al pasar por los pulmones absorbe el oxígeno necesario para que no se envenene y siga viviendo el animal. Esta operación de inspirar oxígeno para renovar la sangre y expulsar el carbónico o gas envenenado que deja la misma sangre se lleva a cabo durante la respiración, la cual tiene como misión el activar el corazón, irritar a la máquina animal y formar el calor natural; operaciones éstas que llevan a evidenciar que la sangre posee vitalidad, no se coagula y como conclusión hace vivir al organismo del animal.

La parte práctica y útil de esta teoría estuvo en relacionar el oxígeno con las asfixias que se producen en los animales cuando éstos se 
ahogan o sofocan. De tal manera que en estos casos si se actúa con rapidez se puede estimular la contractibilidad del corazón a base de calor y de respiración artificial; si la contractibilidad del corazón se vuelve a reanimar por medio del oxígeno entonces se habrá salvado la vida, de lo contrario, el animal morirá.

La cirugía infusoria y transfusoria de la sangre es otra de las técnicas que logra transformar lo vivo por lo vivo. La propuso en $1760 \mathrm{An}$ tonio José Rodríguez en la «Dissertacion primera sobre el uso de los Medicamentos introducidos por las venas, llamado comúnmente Cirugía Infusoria» insertada en su obra Dissertaciones Physico-MathematicoMédicas. El hecho radica en que la sangre es necesaria e indispensable para vivir y que en su movimiento circular alimenta las distintas partes del organismo. De este modo los enfermos que no podían ser alimentados o medicados por la boca se comenzaron a alimentar o medicar por vía intravenosa. La técnica consiste en utilizar una jeringuilla graduada con una aguja incrustada en su remate; con ella se pincha una vena del brazo y se introduce la porción de alimento o medicación en la sangre, cosa que la misma sangre se encarga de repartir por todo el cuerpo.

Los ejemplos siguientes nos ayudarán a ver más claro sobre la técnica infusoria de A. J. Rodríguez. Así, si se administra un purgante por las venas produce el efecto de la purga en el vientre lo mismo que si se hubiese purgado por la boca. Por tanto, si se inyectan por las venas los medicamentos que deben de servir de remedio a la enfermedad éstos tienen el poder de transformar lo enfermo en saludable, bien creando anticuerpos, resistencias, defensas, etc..., o bien destruyendo los virus peligrosos para la salud. Por otra parte, en la época ilustrada se conocieron las distintas reacciones de los diversos elementos químicos, tales como los ácidos en la sangre. Con ello se empezaba a saber algo de las transformaciones que puede realizar el propio organismo después de recibir los alimentos o medicinas por vía intravenosa.

La técnica de la infusión-transfusión no sólo la divulgó A. J. Rodríguez sino que también el miembro de la Regia Sociedad Médica de Sevilla Juan Herrera presentó una disertación titulada Cirugía infusoria $y$ transfusoria (1760), esto es, que no sólo se pueden meter alimentos, medicinas y sangre nueva, sino que de igual modo se puede sacar la sangre enferma y meter la sana. Queda claro que esta técnica de la infusión-transfusión es hoy día muy eficaz y productiva para la medicina sanitaria. 
Otra de las técnicas que afloró durante las últimas décadas del período ilustrado fue la electroterapia. Aquí, ya no se trataba de explicar la enfermedad sino de curarla por medio de los fenómenos eléctricos. Estos comenzaron a irrumpir con Galvani (1737-1798) cuando logró demostrar que los músculos producen corrientes y descargas eléctricas, y Volta (1745-1827) que gracias a su corriente voltaica descubrió la electroquímica y la electrodinámica.

- La electroterapia se comenzó a extender pronto por toda Europa y se utilizó para estimular por medio de las corrientes eléctricas las parálisis de los músculos, o, mejor dicho, para hacer revivir a la materia viva que estaba mortecina. En España también se empleó esta técnica, especialmente en la Regia Sociedad de Sevilla. Entre otros autores podemos citar a José García Cazalla con la disertación sobre La naturaleza de los efluvios eléctricos, si conducen para curar las perlesias que comúnmente se padecen en esta Andalucía Baja (1775); Diego de Vera Limón en Demostraciones eléctricas acomodadas a la Medicina (1797) y Observación por la que manifiestan los favorables y ventajosos efectos de la electricidad en la perlesia inveterada (1799); Cristóbal Nieto Piña con la Dissertación médica en que se manifiestan los útiles resultados de las emanaciones eléctricas para la salud (1789); Francisco González de León en La electrización y si ésta sea remedio para curar la perlesía (1799); Juan Bautista Matoni en Sobre la virtud eléctrica y su aplicación a los casos médicos (1779) y Blas de Fuentes y Santiago que escribió Sobre la electricidad e impotencia (1785). Sin olvidar tampoco a Joaquín de Texada, miembro de la Sociedad Vascongada de Amigos del País que se construyó su propia máquina de electrizar en 1769, con el fin de aplicar la electroterapia a sus enfermos.

Entre las biotecnologías está también la fermentación. Es muy antigua, ya que desde tiempo inmemorial se ha intentado controlar la fermentación del vino y la cerveza. No obstante, en la época ilustrada se avanzó mucho en el control de la fermentación de los alimentos en el estómago, pues la comunidad científica aceptó el jugo gástrico como causa principal de la fermentación de la comida en el saco estomacal, superando con ello a la facultad concoctriz y a la excitación corpuscular. El ácido estomacal transforma, mediante un proceso químico, los alimentos en quilo y éste en sangre o materia nutritiva para el organismo. Así, en España podemos citar especialmente a Virrey y Mange $(+1746)$ que ya en Palma febril (1739) propuso a la "excitación del fermento febril» como causa de las calenturas. También expuso su teoría iatroquímica en el primer tomo del Manual de Cirugía Práctica, Promp- 
tuario Completo (1743) donde habla de la digestión, transformación del quilo en sangre y de la nutrición como proceso biológico ligado al crecimiento.

El proceso de la fermentación de los alimentos en el estómago dio pie a algunos naturalistas como Spallanzani a realizar la experimentación de la digestión in vitro. La técnica era sencilla; se trataba de extraer con una esponja el jugo gástrico de ciertos animales y analizar sus componentes espcialmente el ácido. Ello constituyó un avance importante en la aplicación de las distintas tecnologías para transformar en alimentos o fármacos las diversas plantas, flores y frutos en especial los traídos de la América hispana; un ejemplo es la quina y la chinchona.

En el s. XVIII se despertó entre la comunidad científica de toda Europa la curiosidad por conocer el proceso de la fecundación y las etapas de su desarrollo. De ahí el interés de los embriólogos ilustrados por dominar la materia viva organizada en su forma de generación, regeneración, crecimiento y organización. Por ello, en las últimas décadas del s. XVIII se descubrió la técnica de la fecundación artificial llevada a cabo por algunos biomédicos ilustrados en sus laboratorios, principalmente en batracios como las ranas. La técnica no revestía dificultad, consistía en la extracción de los huevos totalmente vírgenes de una rana hembra y se los rociaba con el semen de la rana macho, comprobando al cabo de unos días que los huevos comenzaban a desarrollar su proceso embriológico. Uno de los primeros en desarrollar las técnicas de fecundación artificial en los animales fue Lázaro Spallanzani (1729-1799) y en el hombre J. Hunter (1728-1793).

El camino estaba abierto y bajo la técnica de la fecundación artificial algunos biomédicos comenzaron el largo proceso de hibridación entre plantas, flores, frutos, animales y hombres, proceso que está en pleno florecimiento en nuestros días por el desarrollo y aplicación de las nuevas tecnologías a la biología/biomedicina.

Por fin, otro fruto de los avances bio-tecnológicos del siglo de las luces fue la inoculación-vacunación como medio para prevenir las viruelas. La técnica de la inoculación antivariólica consiste en introducir de modo artificial la linfa variólica en el organismo, para que ésta actúe en contra de los gérmenes patógenos del propio organismo. La vacuna antivariólica la descubrió el médico inglés E. Jenner (1749-1823), cuyo invento fue acogido y propagado por gran parte de los biomédicos ilustrados europeos, debido a su gran eficacia para erradicar la viruela. 
Los biomédicos españoles también introdujeron y divulgaron la nueva técnica. Entre los defensores de la inoculación se pueden citar a M. Serrano en El mejor específico de las viruelas (1768); también a Francisco Rubio que se vio estimulado a inocular y escribir su Disertación sobre la inoculación de las viruelas (1769) por causa de los éxitos conseguidos por M. Serrano; y a Francisco Salvá y Campillo en La inoculación presentada a los sabios (1777). Timoteo O'Scanlan escribió obras a favor de la inoculación, tales como Práctica moderna de la inoculación (1784), La inoculación vindicada (1786) y Ensayo apologético sobre la inoculación (1792). Los eruditos Sarmiento y Feijóo divulgaron las excelencias de la inoculación; este último en las Memoires de Trevoux. También en la prensa apareció el tema, como en el Diario de Madrid en 1790 con Carta en defensa de la inoculación y Carta sobre la resolución del problema de la inoculación. Finalmente en 1798 una Real Orden de 20 de noviembre vino a confirmar por parte de la autoridad oficial la necesidad de inocular las viruelas.

En cuanto a los defensores y propagadores de la vacuna está Francisco Piguillen (1771-1826) que tradujo los Ensayos sobre la vacuna de François Colon (1801) y después sacó a la luz el folleto de La vacuna en España. No se puede olvidar tampoco a Francisco Sal vá y.Campillo, a Ignacio de Jauregui, a Vicente Martínez con Tratado histórico-práctico de la vacuna (1802); y especialmente a Ignacio María Ruiz de Luzuriaga en el informe que presentó a la Real Academia de Medicina en 1801 titulado Informe imparcial sobre el preservätivo de las viruelas, junto con Papeles sobre la vacuna. El apoyo oficial llegó por una Real cédula de 1805 que imponía a los Hospitales la conservación de la vacuna.

Sin embargo, la labor más importante realizada a nivel de propagación por parte del gobierno de Carlos IV fue la de sufragar los gastos a la expedición a América y Filipinas con el fin de dar a conocer la práctica de la vacuna. Al frente de la expedición iba Francisco Xavier Balmis (1753-1819) y como acompañante José Salvany. Balmis estaba experimentado en el campo de la vacunación, pues en 1803 tradujo el Tratado histórico y práctico de la vacuna de J. L. Noreau de la Sarthe. La expedición zarpó de La Coruña el 3 de noviembre de 1803 y para conservar la vacuna llevaban veinticinco niños que se la transmitían de brazo a brazo. Los ilustres propagadores hicieron una escala en Canarias y tocaron tierra en Puerto Rico, llegando más tarde a Caracas. Este fue el punto de división de la expedición, ya que Balmis se encaminó a Cuba, Méjico y después partió para Filipinas y Macao, regresando por Lisboa en agosto de 1804; mientras que Salvany marchó a Cartagena de Indias y Perú (26). 
En consecuencia, tanto la consideración de la irritabilidad, como las experimentaciones in vitro, o las técnicas de infusión-transfusión, fecundación artificial, hibridación y vacunación constituyeron un principio de práctica y producción de las biotecnologías ilustradas a semejanza de lo que hoy se produce por medio de las altas biotecnologías. Diremos, por tanto, que en las últimas décadas del s. XVIII y primeras del XIX se fue perfilando una amplia base biotecnológica gracias a la unión y/o asociación simbiótica de la tecnología y la experiencia del s. XVII en la biomedicina ilustrada. Esto es lo que nos ha dado pie para acuñar nuestro concepto de biotecnologismo como idea biofilosófica de la tardía modernidad ilustrada, y no dudamos de que este concepto será la base de la ideología biológica del futuro. No obstante, este modelo, que ya pusieron en práctica los biomédicos il ustrados, añadido a los avances biotecnológicos de las últimas décadas, constituye un evento científico de tal magnitud que le convierte desde ya en la gran ilusión de la futura biosociedad, sólo comparable al sueño cartesiano del animal-máquina; pero con una particularidad: que el biotecnologismo en pocas décadas transformará la sociedad en sus formas más profundas de pensar, gobernar, vivir y comportarse.

\section{NOTAS}

(1) Para una mayor ampliación ver Rodríguez Merino, J. M. (1989): Aplicación del modelo mecanicista a la biomedicina en la Ilustración española (T.V. Tosca, D. M. Zapa. ta, M. Martínez B. J. Feijóo, J. Arnau, A. Piquer), pp. 20-75. "Ilustración biomecanicista y razón biofilosófica en Tosca (1651-1723)» (Tesis). Madrid, Ediciones de la U.A.M. (microfichas).

(2) Un estudio más extenso y profundo se puede ver en RodRíguez MERINO, J. M. (1989), pp. 76-162. "De la reconstrucción biomecanicista a la biofilosofía-química en la Ilustración: Diego Mateo Zapata (1664-1745)».

(3) Sobre el biomecanicismo de Martín Martínez consultar a RodRíguez MERINO, J. M. (1989), pp. 163-172. «Biofilosofía escéptica, en Martín Martínez (1684-1734) y Benito Jerónimo Feijóo (1676-1764)».

(4) Arnau, J. (1737): Opus Neoteoricum, I, Valencia, p. 169.

(5) Tanto para el estudio de Arnau como para el de Piquer se puede consultar a Ro DRÍGUEZ MERINO, J. M. (1989), pp. 274-433. «Mecanicismo y Bioexperiencia en la Ilustración valenciana: José Arnau (+1737) y Andrés Piquer (1711-1772).»

(6) Estos tres Mss. inéditos fueron hallados por José M. ${ }^{a}$ RodRíguez MERINo en febrero de 1987 en el Fondo Antiguo de la Facultad de Medicina de la Universidad Complutense de Madrid.

(7) Bedoya y PAREDES, P. (1740): Examen critico de la sangria artificial. Madrid, p. 77.

(8) BEDOYA (1740), pp. 138-143.

(9) Rodríguez, M. (1743), Medicina palpable, Madrid, p. VII, «Prólogo».

180

Asclepio-I-1990 
(10) Rodríguez, M. (1743), pp. IX-X, «Prólogo».

(11) Rodríguez, M. (1743), pp. 230-1, «Dissertacion Physico-Médica, Set. IV».

(12) RodRÍGuez, M. (1743), p. 233.

(13) Bedoya y PAREDEs, P. (1743), El médico desengañado, pp. 186-200.

(14) Rodríguez, A. J. (1741), Palestra crítico médica, tomo IV, Zaragoza, p. 3.

(15) RodRíguez, A. J. (1741), p. 4.

(16) Rodríguez, A. J. (1741), p. 8

(17) Rodríguez, M. (1743), pp. 252-304, Set. XI-XXI

(18) Rodríguez, A. J. (1744), Palest'ra, tomo V, p. 367

(19) Rodriguez, A. J. (1744), tomo V, p. 368.

(20) Rodriguez, A. J. (1744), tomo V, pp. 357-358.

(21) Catalán, J. (1745), Medicina experimental, Madrid, pp. 103-104.

(22) García Hernández, F. (1767), Nuevo Discurso, Madrid, p. 99.

(23) GARCÍA HERNÁNDEZ, F. (1767), p. 171

(24) Ver Rodríguez MERINo (1989), pp. 250-272, «El animal máquina y los argumentos de Feijóo-Martínez».

(25) Consultar Rodríguez Merino (1989), pp. 390-421, «El paradigma experimentalista de Piquer en Madrid».

(26) Para estas interpretaciones históricas consultar a Granjel, L.S. (1979), La Medicina española en el siglo XVIII, Salamanca, pp. 121-125.

\section{BIBLIOGRAFIA}

Bynum, W. F. y otros (1986): Diccionario de Historia de la Ciencia, Barcelona, Herder.

CoHEN, L. (1968): From Beast Machine to Man Machine, New York, Octagon Books.

DELAUNAY, P. (1927): «L'evolution philosophique et medicale du biomecanisme, De Descartes a Boerhaave, De Leibniz a Cabanis», Le progres medical, n. ${ }^{\circ}$ 34, I-III, 20 Aout, pp. 1.289-1.293; n. ${ }^{\circ} 35$, IV, 27 Aout, pp. 1.337-1.342; n. ${ }^{\circ} 36$, V-VII, 3 Sept., pp. 1.369-1.384.

Descartes, R. (1632): Tratado del Hombre (Trad. G. Quintas, Madrid, Ed. Nacional, 1980).

Douzou, P. (1986): Las Biotecnologías, México, Fondo de Cultura Económica.

Chinchilla, A. (1841-1846): Anales Históricos de la Medicina en general y Biográfico-Bibliográficos de la española en particular, vols. 3-4, Valencia, J. Mateu Cervera.

Gracia Guillén, D.; Peset, J. L. (1972): Historia Universal de la Medicina, vol. 3, Barcelona, Salvat Ed., pp. 338-347.

GrmeK, M. D. y otros (1967): Biology History and Natural Philosophy, DenverColorado, Ed. by Breck and Yourgrau, Univ. of Denver, pp. 181-195.

GuYENOT, E. (1941): Les Sciences de la vie aux XVII et XVIIe siecle, Paris, Albin Michel.

HERNÁNDEZ MOREJón, A. (1842-1852): Historia bibliográfica de la Medicina española, vols. VI-VII, Madrid.

KUHN, Th. (1975): La estructura de las revoluciones científicas, Madrid, Fondo de Cultura Económica.

Asclepio-I-1990 
Laín Entralgo, P.; Albarracín Teulon, A. y Gracia Guillén, D. (1973): Historia Universal de la Medicina, vol. 5, Barcelona, Salvat Ed., pp. 45-61.

LENOBLE, R. (1971): Mersenne on la naissance du mecanisme, Paris, J. Vrin.

LOPEZ PIÑERO, J. M. (1969): Introducción de la ciencia moderna en España, Barcelona, Ariel.

LóPEZ PIÑERO, J. M. y otros (1983): Diccionario histórico de la ciencia moderna en España, 2 vols., Barcelona, Ed. Península.

MuÑoz, E. (1987): «La biodirección, un reto de la política científica y tecnológica", Arbor CXXVIII, Octubre, pp. 11-29.

PeSET, J. L. (1973): Historia Universal de la Medicina, vol. 5, Barcelona, Salvat Ed., pp. 99-103.

PeSET, J. L.; LAfUENTE, A. (1988): Historia de España, La Ilustración XXX-1, Madrid, Espasa Calpe, pp. 349-394

Rivadulla, A. (1987): "Ludwik Fleck: la irrupción de la orientación histórico sociológica en epistemología», Arbor, CXXVIII, Octubre, pp. 31-61.

RoGeR, J. (1963): Les Sciences de la vie dans la pensée francaise du XVIIIe, $\mathrm{Pa}$ ris, Armand Colin.

SANCHO DE SAN ROMÁN, R. (1961): Catálogo de las disertaciones y memorias de la Regia Sociedad Médica de Sevilla (1736-1819).

Schuhl, P. M. (1938): Mechanisme et Philosophie, Paris, Alcan.

VICENTE, M.; RENART, J. (1987): Ingeniería genética, Madrid, C.S.I.C. 